\title{
Method and System for Real-Time Audio and Video Transmission of Colonoscopy Exams: A Study Case on a Local Network
}

\author{
Renato Bobsin Machado ${ }^{1}$, Huei Diana Lee ${ }^{1}$, Joylan Nunes Maciel $^{2}$, Richardson Floriani Voltolini ${ }^{3}$, An- \\ dré Gustavo Maletzke ${ }^{1}$, Claudio Saddy Rodrigues Coy ${ }^{4}$, João José Fagundes ${ }^{4}$, Feng Chung Wu ${ }^{1,4}$ \\ ${ }^{1}$ State University of West Parana (UNIOESTE), Foz do Iguaçu (PR), Brazil \\ ${ }^{2}$ Federal University of Latin-American Integration (UNILA), Foz do Iguaçu (PR), Brazil \\ ${ }^{3}$ Center for Higher Education of Foz do Iguaçu (CESUFOZ), Foz do Iguaçu (PR), Brazil \\ ${ }^{4}$ State University of Campinas (UNICAMP), Campinas (SP), Brazil \\ renatobobsin@gmail.com, hueidianalee@gmail.com, joylan@gmail.com, rfvoltolini@gmail.com, andregusta- \\ vom@gmail.com, claudiocoy@gmail.com, ij.fagundes@terra.com.br, wufengchung@gmail.com
}

\begin{abstract}
Telemedicine can facilitate the examination and diagnosis of patients in locations with lack of resources and medical experts. This paper presents an innovative method and a computer system that allows real-time text, voice and video interaction among participants and data sharing of colonoscopy exams over the Internet. The proposed method implements a medical database which will be further explored using data mining methods. The functionalities and performance of the method were evaluated, in a local network, with the development of a computational system. The results validated the solution showing its applicability in colonoscopy exams.
\end{abstract}

Keywords: Telemedicine, colonoscopy, audio and video streaming, real time interaction.

\section{Introduction}

The development of the technological area, in particular, Information Technology and Communication (ICT), has enabled the application of a great diversity of computing resources to aid different areas of knowledge [1,2].

The application of such technologies to health care has promoted important contributions and stimulated the development of multidisciplinary research $[1,2,3,4]$. Due to the application of ICTs in different areas of medicine, it was made necessary the definition of certain concepts related to computer systems, as well as the establishment of standardizations. The main categories of applications defined are Hospital Information System (HIS) [5], Radiology Information System (RIS) [5] and Picture Archiving and Communication Systems (PACS) [5]. Also, the need for integration and interoperability among these systems has stimulated the development of protocols for this purpose. Some of the well established and widely accepted protocols in health care include Digital Imaging Communications in Medicine (DICOM) [6] and Health Level Seven (HL7) [5, 7].
In contrast to this progress in research and technology products applied to health care, it is observed that important tasks used for optimization of procedures related to the medical field are not automated or are not widely accessible. These conditions exist mainly due to the lack of appropriate computer resources [5].

The Laboratory of Bioinformatics (LABI) from the Western Paraná State University (UNIOESTE) in partnership with the Coloproctology Service of the Faculty of Medical Sciences from the State University of Campinas (UNICAMP) has been developing research in the fields of Telemedicine $[8,9,11]$ and Intelligent Analysis of Medical Data $[10,12]$. Most of these researches aim to facilitate the remote monitoring of patients and medical procedures, as well as to build databases with information about these procedures applying data quality concepts, allowing the application of Intelligent Data Analysis, thus aiding the diagnosis and prevention of specific diseases [30].

One of such projects is related to the design of a technological solution, classified as HIS and PACS, for the management, following and remote interaction of experts during colonoscopy exams. Furthermore, the solution includes building a structured medical database for the application of data mining methods. With this database it will be possible to provide diagnostic and prevention aid for colonoscopy $[9,13]$.

As being part of the project previously mentioned, this paper presents a computer system that communicates with hospital video-colonoscopy equipments implementing the proposed method. The solution allows real-time manipulation and transmission of streams of audio, video and images from medical exams through the Internet [13]. Furthermore, it is possible in situ or remote interaction among medical specialists during exams.

Systems in telemedicine that use audio and video streaming, such as the one proposed in this work, can be evaluated by several criteria such as number of frames per second (FPS) sent and received [16], audio and video bitrate [16] bandwidth consumption [17], transmission latency [17], among others. Therefore, this paper also 
presents a quantitative performance evaluation concerning the FPS rate of the transmitted and received video. The FPS value represents the number of frames (images) displayed every second, being the attribute responsible for the sense of continuity when viewing a video $[16,17]$.

The rest of this paper is organized as follows. The description and analysis of the method is covered in Section 2 , where the technologies, the architectural model and the experimental evaluation approach are described. Section 3 presents the results related to the method development and the performance experiments conducted. In Section 4 we discuss the results of the performance evaluation and, finally, Section 5 presents the concluding remarks and future work.

\section{Materials and Methods}

The computational system that implements the proposed method was developed following the recommendations from software engineering through the use of a software development process based on prototyping [19] and using the Unified Modeling Language (UML) [20].

From the domain study and joint meetings with colonoscopy field experts, the system developed included the following functional requirements:

- Private, confidential and secure access to the system and its information;

- Maintenance of information related to professionals, patients, exams, institution, medical equipment and auxiliary data;

- Resources to capture, store and manage images and videos during colonoscopy exams;

- Functionality to export patient data and exams images to DICOM format;

- Resources that allow interaction among participants during execution of exams, through text messages, voice and video;

- Allowing health care professionals to follow and actively participate in performing colonoscopy exams, even remotely, by capturing and sharing images of examinations with other participants, using browsers (Web Browser) with Internet access;

- Provide a simple, functional and friendly computer interface;

- Securely provide data from previous exams through browser (Web Browser) and Internet connection;

- Development of a structured database that allows access to data and images from colonoscopy exams, allowing application of knowledge discovery techniques.

After defining the requirements and observing peculiarities of the problem, the technologies to be applied in the computational solution were studied and selected. The overall system architecture was projected and a model to evaluate experimental performance analysis was devel- oped. These definitions are presented in the following sections.

\subsection{Computational Tools}

The computer system was developed according to the Model-View-Controller (MVC) pattern [19] using the Java programming language [21], the JBOSS Application Server 4.2 [22], the Red5 ${ }^{1}$ Streaming Server 1.0 RC11, the development framework JBOSS Seam 2.1.2 [23] and the Database Management System (DBMS) MySQL 5.1.42 [24].

The visual interface of the system was implemented using Flex 4.0 programming language [25]. The interaction and communication between the classes developed in Java and Flex were performed by remote objects and functions available in the Flamingo ${ }^{2}$ framework. Figure 1 presents these technologies following the layered definition of the MVC pattern.

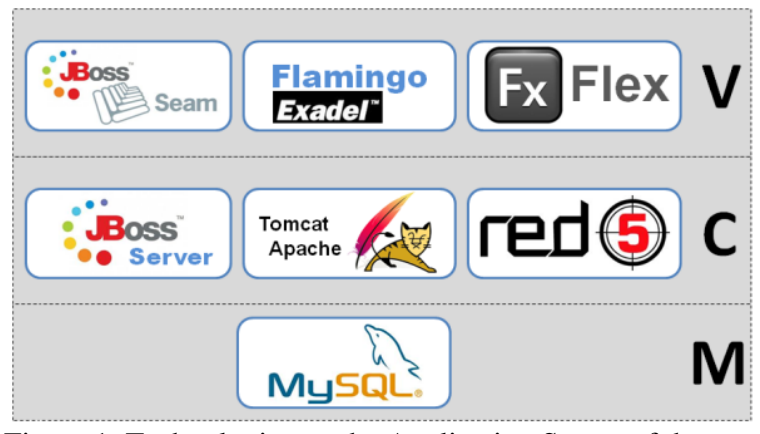

Figure 1. Technologies on the Application Server of the proposed computational solution.

\subsection{Architectural Model}

From the functional requirements listed and the technologies selected, an architectural model was built. The components and logical operation of this model are shown below (Figure 2):

- Endoscopic Procedures Room (EPR): is where colonoscopy examinations are performed. In this room there is a Colonoscopy Equipment (CE) and a Local Execution Unit (LEU), ie, a system which function is to acquire and forward the exam's video to the Application Server (AS), located at the Central Management (CM);

\footnotetext{
${ }^{1}$ The documentation can be obtained at <http://www.red5.org/support>.

${ }^{2}$ More detail available at <http://exadel.org/flamingo $>$.
} 


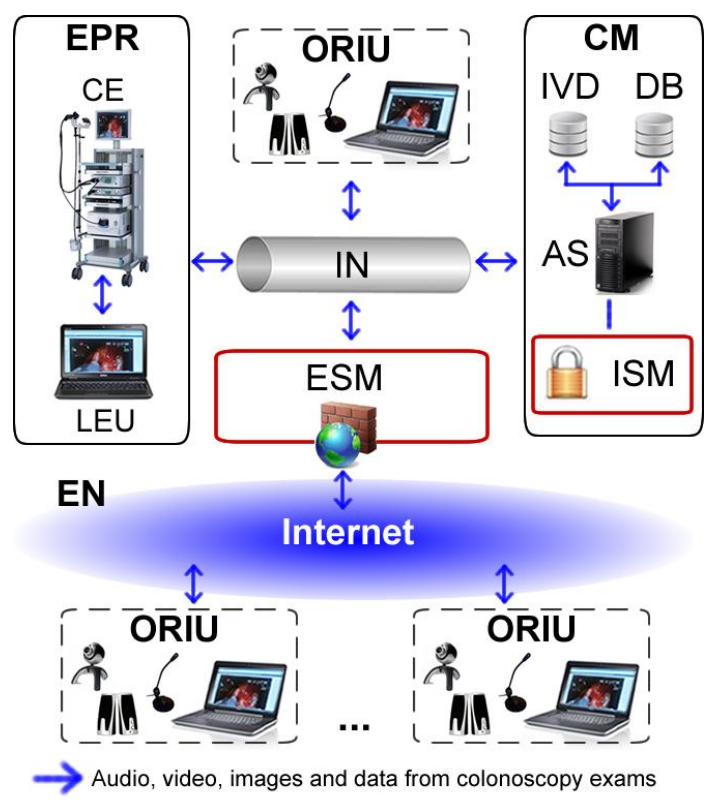

Figure 2. Architectural model of the solution.

- Observation and Remote Interaction Units (ORIU): are computers with hardware and software components available to medical experts used to remotely observe, in real time, the execution of colonoscopy exams. Through ORIU it's possible the interaction with other professionals at the EPR and/or at other ORIUs, provided that there is an Internet connection;

- Central Management (CM) has the function of managing all the computing resources used on examinations. It consists of the Application Server (AS), the Database (DB), the Images and Video Database (IVD) and the Internal Security Module (ISM), the latter described in [11]. The AS is responsible for access control, reception, management and distribution of audio and video streams between the LEU and the ORIUs. The DB is where data from exams and medical reports are physically stored. The IVD organizes and stores the images and videos of colonoscopy exams. This database will allow, in the future, the application of techniques for intelligent data analysis. Finally, the ISM is responsible for security on users management and policies for data transmission between the LEU and ORIUs;

- Internal Network (IN): hardware and software devices used for communication and transmission of data, video, images and audio, within the institution where the exams are performed;

- External Security Module (ESM): responsible for the safety and protection against attacks and unauthorized access to the institution's computer where the exam is being held, on behalf of external networks [11];
- External Network (EN) (ie, Internet): is the communication network external to the institution, named simply as Internet in this work.

Aiming the evaluation of the solution and validation of the proposed method, we carried out an experimental performance evaluation model, which is described in the next section.

\subsection{Performance Evaluation Model}

The experimental evaluation model was designed to perform the validation and the performance analysis of audio and video streaming transmissions over a Gigabit Ethernet 803.3z local network [17], common in healthcare and education institutions.

The evaluation consisted on collecting and analyzing the sending and receiving rate of frames per second (FPS) of a streaming video broadcasted over the local network. This video represents a real colonoscopy examination and FPS values were collected from different computers connected to the local network. After that, the FPS values obtained were statistically evaluated. The following sections present details of this process, addressing the components and the design of the experimental evaluation.

\section{Components}

The experimental model was composed by the following components (Figure 3):

- Colonoscope Simulator: Digital camcorder model JVC Everio GZ HD 520 responsible for the generation and simulation of the audio and video from a colonoscopy exam;

- Emitter: computer responsible for the acquisition, generation and transmission of multimedia stream (colonoscopy exam audio and video) to the Server. The software $\mathrm{VCam}^{3}$ was used on this computer to simulate the webcam that originates the audio and video stream;

- Server: computer responsible for receiving and relaying the exam's multimedia stream to Ethernet and WiFi Clients;

- Ethernet Client: computer responsible for the reception and presentation of multimedia stream through a standard Gigabit Ethernet network connection;

- WiFi Client: computer responsible for the reception and presentation of multimedia stream through a Wireless Fidelity (WiFi) 803.11b standard network [17], connected to a Gigabit Ethernet [17];

- Access Point: WiFi access point, model TP LINK TL WA-901ND with transmission speed of 54 Mbps;

- Gigabit Ethernet Local Network: communication network based on Gigabit Ethernet standards.

\footnotetext{
${ }^{3}$ More details see <http://www.e2esoft.cn/vcam>.
} 


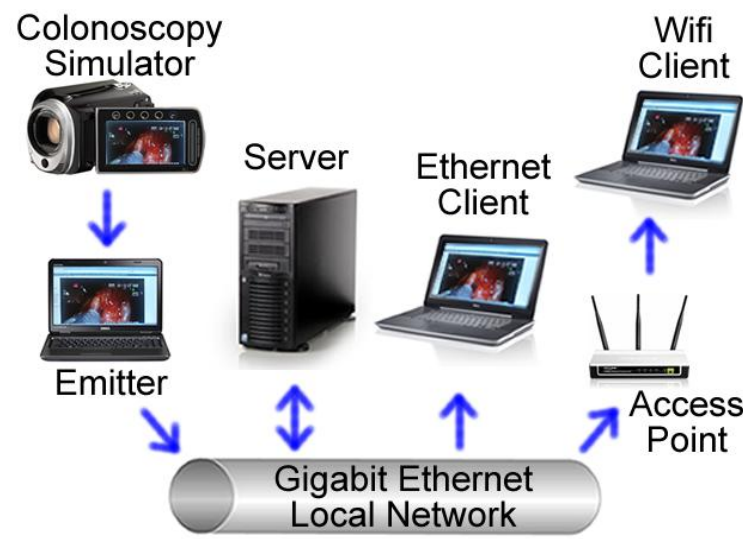

$\rightarrow$ Audio and video from colonoscopy exams

Figure 3. Components of the Experimental Evaluation Model.

Table 1. Experimental model configuration of hardware and software components.

\begin{tabular}{|c|c|c|c|c|}
\hline & CPU & RAM & $\begin{array}{c}\text { Network } \\
\text { Interface }\end{array}$ & OS \\
\hline Server & $\begin{array}{c}\text { Intel Core 2 } \\
\text { Duo CPU } \\
2.20 \mathrm{GHz}\end{array}$ & $\begin{array}{c}\text { DDR 2 } \\
4.0 \mathrm{~GB}\end{array}$ & $\begin{array}{c}\text { Broadcom NetXtreme } \\
\text { BCM5755 Gigabit } \\
\text { Ethernet }\end{array}$ & $\begin{array}{c}\text { Linux Debian } \\
\text { Kernel 2.6.32 } \\
64 \mathrm{bit}\end{array}$ \\
\hline Emitter & $\begin{array}{c}\text { Intel Core i7 } \\
\text { CPU 2.00GHz }\end{array}$ & DDR 2 \\
$6.0 \mathrm{~GB}$ & $\begin{array}{c}\text { JMicron PCI Express } \\
\text { Gigabit Ethernet }\end{array}$ & $\begin{array}{c}\text { Windows 7 } \\
\text { Profes. 64bit } \\
\text { SP1 }\end{array}$ \\
\hline $\begin{array}{c}\text { Ethernet } \\
\text { Client }\end{array}$ & $\begin{array}{c}\text { Intel Core 2 } \\
\text { Quad CPU } \\
2.83 \mathrm{GHz}\end{array}$ & $\begin{array}{c}\text { DDR 2 } \\
4.0 \mathrm{~GB}\end{array}$ & $\begin{array}{c}\text { Intel 82567 LM-3 } \\
\text { Gigabit Ethernet }\end{array}$ & $\begin{array}{c}\text { Windows 7 } \\
\text { Profes. 32bit } \\
\text { SP1 }\end{array}$ \\
\hline $\begin{array}{c}\text { WiFi } \\
\text { Client }\end{array}$ & $\begin{array}{c}\text { Intel Core i5 } \\
2410 \mathrm{M} \mathrm{CPU} \\
2.30 \mathrm{GHz}\end{array}$ & $\begin{array}{c}\text { DDR 2 } \\
4.0 \mathrm{~GB}\end{array}$ & $\begin{array}{c}\text { Dell Wirelles 1702 } \\
\text { b/g/n }\end{array}$ & $\begin{array}{c}\text { Windows 7 } \\
\text { Home 64bit } \\
\text { SP1 }\end{array}$ \\
\hline
\end{tabular}

On Table 1 hardware configuration (CPU, RAM and network card) and operating system (OS) of the computers used in the experiments are displayed.

Access to the computer system, on all computers was done through the Mozilla Firefox 18.0.2 browser, with Java 7 U13 virtual machine and Adobe Flash Player 11.5 R502 plug-in.

\section{Experimental Design}

As mentioned before, the video used for the experiment was generated by the colonoscope simulator (Digital Camcorder JVC Everio). The Emitter computer was responsible for sending audio and video to the Server, which made the transmission of these flows to the Ethernet and $\mathrm{WiFi}$ Clients.

The video considered in the experiment had the following properties:

- Resolution of $1024 \times 768$ pixels;

- Rate of 25 FPS;

- Bitrate of $13000 \mathrm{Kbps}$;

- Transmission quality equal to $100 \%$ (without use of compression);

- Sorenson Sparcom video codec [26].
Audio features adopted were:

- Speex ${ }^{4}$ audio codec;

- Bitrate of $34.2 \mathrm{Kbps}$

The experiment was established according to the following steps:

a) Definition of dates and times for experiments: five days a week (Monday to Fri-day), with two experiments by period (shift). The set times were 10:00 AM, 11:00 AM, 3:00 PM and 4:00 PM;

b) Generation of the video used in the experiments: corresponds to a real colonoscopy video, used with permission of the patient. The video was reproduced by the JVC Everio camcorder with video settings previously defined;

c) Manual termination of unnecessary software processes on client computers;

d) Start of the AS;

e) Initiation and configuration of the VCam software on the Emitter computer;

f) Connection of Ethernet and WiFi Client computers to the AS;

g) Activation of audio and video streaming on the Emitter computer;

h) Experiment execution;

i) Storage of results corresponding to FPS values;

j) Statistical analysis of the results.

The sample space consisted of 20 experimental runs, each one lasting 30 minutes. On each computer (Emitter, WiFi Client and Ethernet Client) data were collected regarding the number of FPS once per second, totaling 1800 samples per run.

The FPS rate of the Emitter computer was considered the control group. Results were organized and analyzed using Friedman nonparametric statistical test and post-test Dunn [27]. In the analysis, we compared FPS values between Emitter, Ethernet and WiFi Client computers, and also the percentage of samples with FPS values lower than 10 , ie, the ones with video crashes perceptible to humans [28, 29, 39].

\section{Results}

The computational solution was developed according to the architectural model described in Section 2.2.

Figure 4 shows the system's authentication screen (login).

Figure 5 shows a screen of the examination following with the available options (setup, record video and capture image) and Figure 6 illustrates the examination analysis screen, as well as information from the respective exam.

\footnotetext{
${ }^{4}$ More details see <www.speex.org>.
} 


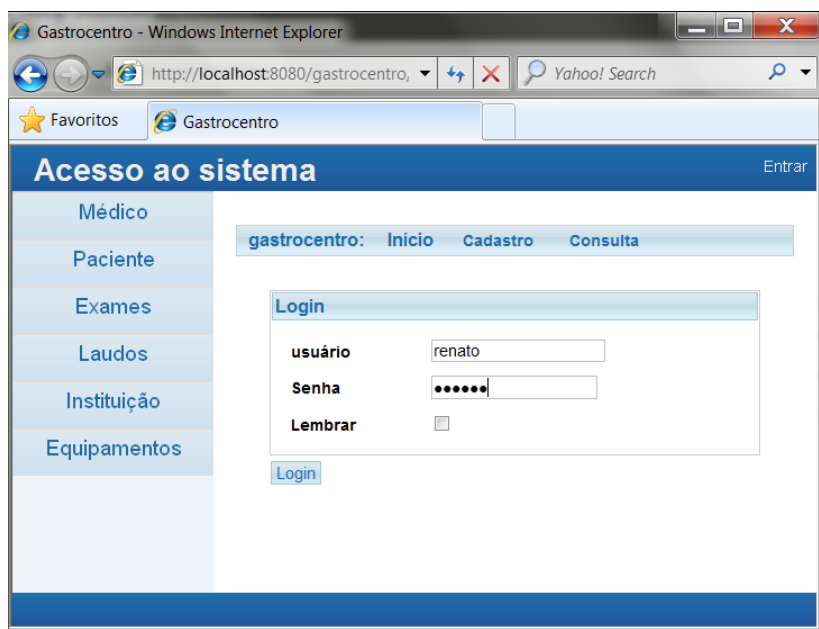

Figure 4. User authentication screen of the developed system.

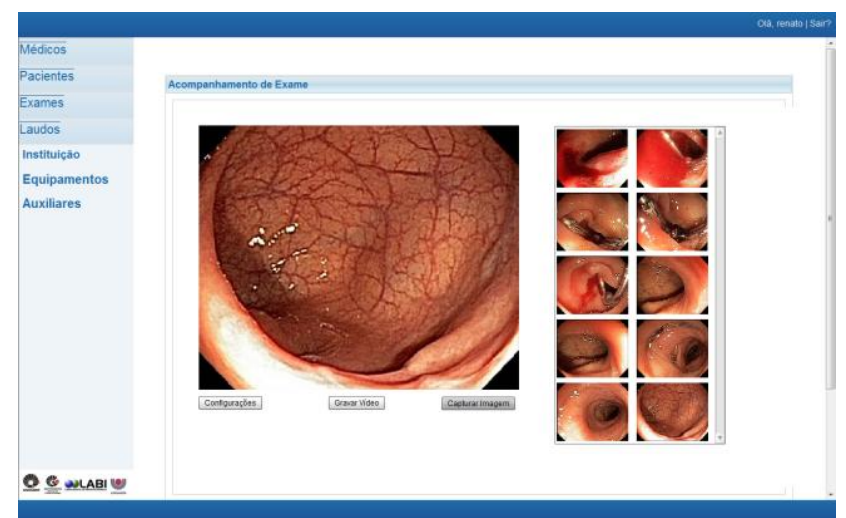

Figure 5. Examination following screen of the developed system.

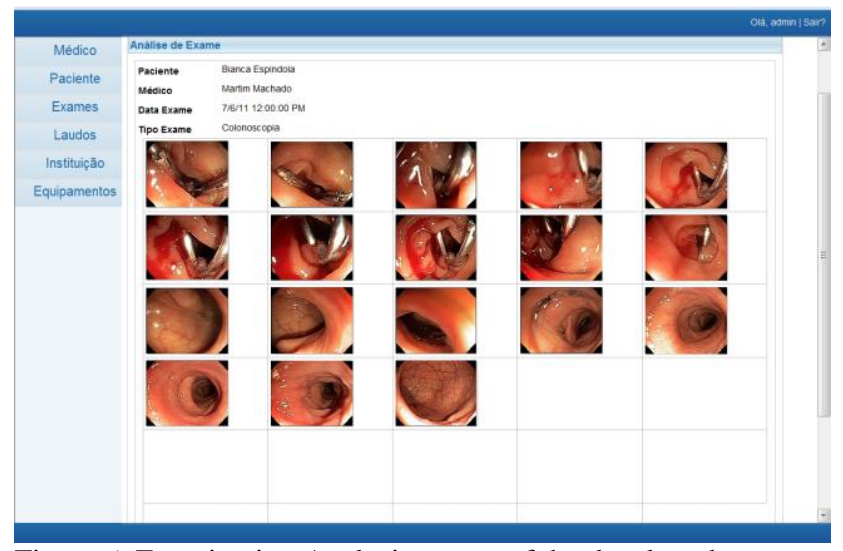

Figure 6. Examination Analysis screen of the developed system.

Table 2 presents the average FPS $(\bar{x})$ and Standard Deviation (SD) rates of FPS sent by the Emitter and received by Ethernet and WiFi Clients, organized by day (1 to 5) and periods (morning - M and afternoon - A, respectively).

Columns $\bar{x}$ (M) and $\bar{x}$ (A) exhibit the general FPS average and SD of each computer in the morning and afternoon. In Figure 7, the FPS average rate and its SD are graphically displayed for each computer, considering all executions for each component.

Table 2. Daily FPS average of five mornings (M1 to M5) and five afternoons (A1 to A5) samples per client and its standard deviation.

\begin{tabular}{|c|c|c|c|c|c|c|c|}
\hline \multicolumn{2}{|c|}{ FPS } & M1 & M2 & M3 & M4 & M5 & $\bar{x}(\mathbf{M})$ \\
\hline \multirow{2}{*}{ 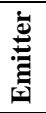 } & $\bar{x}$ & 23.80 & 23.59 & 23.85 & 23.83 & 23.61 & 23.73 \\
\hline & DP & 0.64 & 0.83 & 0.63 & 0.64 & 0.95 & 0.7 \\
\hline \multirow{2}{*}{ 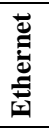 } & $\bar{x}$ & 21.25 & 21.18 & 21.51 & 21.44 & 21.20 & 21.5 \\
\hline & DP & 1.70 & 1.76 & 1.72 & 1.80 & 2.32 & \\
\hline \multirow{2}{*}{ 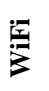 } & $\bar{x}$ & 20.84 & 20.79 & 21.10 & 20.97 & 21.03 & 20.95 \\
\hline & DP & 2.84 & 3.11 & 2.77 & 2.87 & 2.78 & 2.88 \\
\hline
\end{tabular}

\begin{tabular}{|c|c|c|c|c|c|c|c|}
\hline \multicolumn{2}{|c|}{$F P S$} & A1 & A2 & $\mathbf{A 3}$ & A4 & A5 & $\bar{x}(\mathbf{A})$ \\
\hline \multirow{2}{*}{$\begin{array}{l}\stackrel{\grave{\Xi}}{\Xi} \\
\text { 竞 }\end{array}$} & $\bar{x}$ & 23.97 & 23.95 & 23.67 & 23.61 & 23.96 & $\begin{array}{r}23.83 \\
\end{array}$ \\
\hline & DP & 0.46 & 0.49 & 0.76 & 0.83 & 0.48 & 0.64 \\
\hline \multirow{2}{*}{ 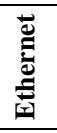 } & $\bar{x}$ & 21.42 & 21.48 & 21.36 & 21.22 & 21.65 & 21.43 \\
\hline & DP & 1.82 & 1.70 & 1.74 & 1.72 & 1.71 & 1.74 \\
\hline \multirow{2}{*}{ 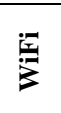 } & $\bar{x}$ & 21.27 & $\begin{array}{c}21.09 \\
-\end{array}$ & 21.16 & 20.93 & 21.28 & 21.15 \\
\hline & DP & 2.83 & 2.82 & 2.51 & 2.80 & 2.64 & 2.72 \\
\hline
\end{tabular}

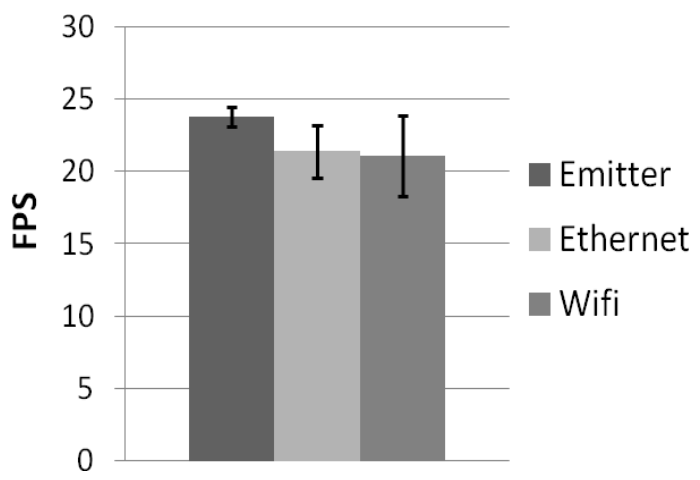

Figure 7. Overall FPS average rate for each computer.

Table 3 shows the statistical analysis for morning and afternoon periods, showing the existence of Significant Difference (Diff) p-value ( $P$-value $)$ obtained in comparisons between the Emitter, Ethernet and WiFi computers, considering all samples. 
Table 3. Comparative analysis between the FPS distributions for each computer.

\begin{tabular}{|c|c|c|}
\hline & $\begin{array}{c}\text { Morning } \\
\text { Comparisons }\end{array}$ & $\begin{array}{c}\text { Afternoon } \\
\text { Comparisons }\end{array}$ \\
\hline Computers & P-Value & P-Value \\
\hline Emitter vs. Ethernet & $<0.0001$ & $<0.0001$ \\
\hline Emitter vs. WiFi & $<0.0001$ & $<0.0001$ \\
\hline \multicolumn{2}{|c|}{0.1183} & $>0.9999$ \\
\hline Computers & Morning and Afternoon \\
\hline Comparisons
\end{tabular}

Table 4 shows the frequency percentage of seconds that the FPS value was below and above or equal to 10 , which is the rate for the limit of human perception [28, 29, 39].

Table 4. Relative frequency of occurrence of FPS below and above or equal 10 .

\begin{tabular}{|c|c|c|}
\hline \multicolumn{3}{|c|}{ above or equal 10.} \\
\hline EPS Value & $<\mathbf{1 0}$ & $>=\mathbf{1 0}$ \\
\hline Emitter & $0.01 \%$ & $99.99 \%$ \\
\hline WiFi & $0.06 \%$ & $99.94 \%$ \\
\hline
\end{tabular}

\section{Discussion}

The focus of most researches in telemedicine involves building databases of exams, allowing doctors to make the diagnosis remotely, but without the possibility of realtime observation of exam's data and interaction among those health care professionals [31, 32, 33, 34]. Other solutions provide remote monitoring of vital signs of patients and equipment data, however, to the best of our knowledge, are not applied to exams with flows of video and audio [35, 36, 37].

The computational system presented in this work covers the characteristics of HIS and PACS systems and uses the DICOM protocol, a globally accepted standard for handling images and data from medical field [6]. This feature enables interoperability of the solution with various medical equipments. In addition, the following characteristics differ from other developed system [1, 4, 8, 9, 11, 13, 31, 33, 34, 35, 36, 37]:

- It allows access, share and real-time following of remote colonoscopy exams during its realization, with features of video and image manipulation, such as magnification and image capture;

- The system enables real-time interaction through audio, video and text messages between medical experts during colonoscopy exams;
- It enables examinations to be performed in locations where there are lack of medical experts without compromising the effectiveness of the procedure, and in many cases, avoiding the need to shift patients to distant cities which have such experts;

- It allows medical specialists to work remotely, on the analysis and preparation of reports and diagnostics, during and after the colonoscopy exams;

- It deploys standardized mechanisms for management of patient data and examinations for health care areas, building a database of images, videos and data from exams designed for future application of artificial intelligence techniques and data mining.

The developed model requires an Internet connection and is based on a web environment, running from web browsers (common programs for Internet access such as Internet Explorer $\AA$, Mozilla Firefox ${ }^{\circledR}$ and Google $\AA$ Chrome).

This feature allows greater flexibility and access from health care professionals in remote areas, helping to minimize the impact of medical doctors' shortage on further and isolated areas [15]. Furthermore, the architecture of the solution is independent of hardware platform and operating system, facilitating the addition of new features as well as the extension of the solution to other fields of medicine.

The prototype has been validated on Windows and Linux operating systems, using the web browser Mozilla Firefox ${ }^{\circledR}$. All features involving data transmission between participants, both local and remote, are held in an encrypted manner, ensuring privacy of data and users.

One of the advantages of the system is the use of tools based on open source software, which reduces cost of development, still maintaining an intuitive and friendly interface. For transmission of audio and video streamings it was applied RED5 server, a free software that met the requirements of the application. Future work will analyze the cost benefit of using other streaming servers, such as Wowza $^{5}$ and FMS ${ }^{6}$.

To validate the developed system and its functionalities, experiments were performed using the experimental model defined in Section 2.3.

It was used a video with resolution of $1024 \times 768$ pixels for the experimental evaluation, which is similar to the maximum resolution used in most of the video monitors of the colonoscopes used by health care services. Another decision was to evaluate performance by applying the maximum possible video quality, that is, without use of compression algorithms. The video bitrate was 13000 Kbps, reproducing the value obtained in a real colonoscopy video.

As mentioned before, the considered experimental environment was configured with the characteristics of

\footnotetext{
${ }^{5}$ More details see <http://www.wowza.com>.

${ }^{6}$ More details see <http://www.adobe.com/ products/adobe-mediaserver-family.html>
} 
bandwidth and equipment used in most computer networks present on Education and Research Institutions in Brazil. WiFi network was evaluated because of its increasingly applicability in clinics and hospitals, as it is adaptive and does not require structured cabling [17]. Thus, the objective of the experiments was to evaluate the performance of the method through the variable FPS in order to simulate the precision of the method in real institutional environment.

According to the results it was observed that the Emitter computer, configured to send the video at 25 FPS, generated a lower (23.73) FPS rate. This indicates that there is a loss of about $5 \%$, in the video capture and decode process, but without generating sensitive delays to human perception [29, 39]. This loss is influenced by the Emitter load of receiving, processing and transmitting the video.

Data presented in Table 2 were analyzed in relation to the existence of a statistically significant difference (pvalue $<0.05)$ between the Emitter, Ethernet and WiFi Client computers.

The analysis of the results showed statistically significant differences ( $p$-value $<0.0001$ ) for all the comparisons among Clients and Emitter, both considering morning and afternoon periods, and all experiments. Exceptions were found at comparison between Ethernet and WiFi clients in all sets (mornings, afternoons and all experiments).

This result indicates that the mean of communication, Gigabit Ethernet and WiFi, did not statistically influenced the FPS rate of the transmitted video.

Overall, the similarity of the experimental results in the morning and afternoon through the local network was an expected result, since in local network connections are established peer to peer on the switch, with no interference or shared bandwidth between concurrent sessions [17].

According to literature [28, 29, 39], the rate for the human perception of continuity of a video is approximately 10 FPS. In this sense, it is observed in Table 4 that the Emitter and Ethernet Client computers during over $99 \%$ of the experimental time the video was displayed with SPF values above 10 . This result demonstrates that the developed solution meets the needs of the application, running on a Gigabit Ethernet network with the video (resolution, bitrate and FPS) and audio (bitrate) characteristics used in the actual health care and research institutions. Networks with these characteristics are common in today health-care institutions such as UNICAMP.

Also in Table 4 it is shown that FPS values to the $\mathrm{WiFi}$ Client computer indicates that, nearly $1.8 \%$ of the time, there were perceptible glitches in the experiment's video, namely FPS values below 10. This result was due to the unguided WiFi communication medium used by the WiFi Client computer. In WiFi transmissions delays are inherent in the process of conversion between digital signal and radio waves as well as signal interference caused by communication devices that use radio waves and obsta- cles on the course [17]. Nonetheless, this demonstrates that the local network statistically reduces transmission performance of video, while not influencing the medical specialist's perception of continuity on the video [39].

\section{Concluding Remarks}

The developed system can be applied to reduce the time of diagnosis and report generation, facilitating the realization of exams in places where there is lack of resources or medical experts. The usability and performance analysis of the architectural and experimental evaluation models demonstrates and validates that the solution meets the functional requirements defined in Section 2. In addition, a particularity of the developed method is that the system's architecture and the use of standardized protocols allow their application in other areas of the medical field.

Performance analysis of other characteristics, such as latency and bandwidth usage, and evaluations of the system with different clients using the Internet comprise further work.

In general, the proposed method is innovative because, besides adding real-time experiment follow, secure transmission, data sharing tests, interaction between experts, it yet allows the construction of a database, in the attribute-value format, consisting of data, images and videos of colonoscopy exams. Intelligent techniques for knowledge discovery will then be applied to this database in order to aid the prediction and diagnosis of diseases in colonoscopy exams.

\section{References}

[1] Lee HD, Costa LHD, Ferrero CA, Coy CSR, Fagundes JJ, Machado RB, Wu FC. Protótipo de um sistema de gerenciamento de protocolos de câncer colorretal. Revista Brasileira de Coloproctologia (Impresso), v. 31, p. 1-7, 2011.

[2] Shortliffe EH, Cimino JJ. Biomedical informatics: computer applications in health care and biomedicine. $3 a$ ed. New York: Springer Science+Business Media. 2006.

[3] Wilson J, Lee HD, Silva AC, Costa LHD, Espindola B, Coy CSR, Fagundes JJ, Wu FC. Adoção de Medidas de Qualidade de Dados para o Desenvolvimento de Sistemas Biomédicos. In Conferência Brasileira de Dinâmica, Controle e Aplicações, 2011.

[4] Caritá EC. Sistema de gerenciamento de imagens para ambiente hospitalar com suporte à recuperação de imagens baseada em conteúdo [Tese de Doutorado]. Ribeirão Preto: Universidade de São Paulo, 2006.

[5] Yu L, Jihong W. PACS and digital medicine: essential principles and modern practice. Boca Raton: Taylor and Fracis Group, SBN: 13:978-1-4200-8366-8, 2011.

[6] Pianykh OS. Digital Imaging and Communications in Medicine (DICOM): A practical introduction and sur- 
vival guide. Boston: Editora Springer, ISBN 354074570X, 2008.

[7] HL7. Join HL7 International. 2011. [acesso em: 29 jul. 2012]. Disponível em: 〈http://www.hl7.org/>.

[8] Maciel JN, Machado RB, Wu FC, Lee HD, Fagundes JJ, Góes JRN. Protótipo de Conferência Multimídia e Transmissão de Dados de Experimentos Médicos em Tempo Real pela Web. In VI Workshop de Informática Médica - WIM, 2006.

[9] Machado RB, Lee HD, Leal FL, Ayrizomo MLS, Coy CSR, Fagundes JJ, WU FC. Prototype of a computer system for managing data and video colonoscopy exams. J. Coloproctol., vol. 32, n.1, pp. 50-59, 2012.

[10] Oliva JT and Ferrero CA. Modelos para Diferenciação de Tecidos Cólicos em Imagens de Coloscopia. In XIII Congresso Brasileiro de Informática em Saúde, 2012.

[11] Machado RB, Wu FC, Lee HD, Ayrizomo MLS, Leal RF, Coy CSR and Fagundes JJ. Protótipo de um Sistema Computacional para o Gerenciamento de Dados e de Exames de Videocolonoscopia. In Revista Brasileira de Coloproctologia - Suplemento, 2011.

[12] Wu FC, Lee HD, Ferrero CA, Coy CSR, Fagundes JJ, Machado RB and Costa LHD. Development of an Ontology-based Approach for Mapping High Digestive Endoscopy Medical Reports into Structured Databases. In ALIO-INFORMS Joint International Meeting, 2010.

[13] Lee HD, Machado RB, Ferrero CA, Coy CSR, Fagundes JJ, Wu FC. Modelo computacional para o gerenciamento de dados e exames de pacientes para o acompanhamento remoto por meio de conferência multimídia. Revista Brasileira de Coloproctologia (Impresso), v.30, p.399-408, 2010.

[14] Lee HD, Monard MC, Honorato DF, Lorena AC, Ferrero CA, Maletzke AG, Zalewski W, Coy CSR, Fagundes JJ and Wu FC. Mapping Unstructured Data in Digital and Printed Documents Into Attribute-value Tables. In Towards a Trans-disciplinary Technology for Business Intelligence, Gathering Knowledge Discovery, Knowledge Management and Decision Making. Shaker Verlag, p198-209, 2011.

[15] UFMG, Avaliação nacional da demanda de médicos especialistas percebida pelos gestores de saúde. Relatório Técnico da Universidade Federal de Minas Gerais, Falculdade de Medicina. Disponível em <www.nescon.medicina.ufmg.br/biblioteca/imagem/2 466.pdf>. Acesso em 21 mar 2013, Belo Horizonte, 2009.

[16] Bhaskaran V, Konstantinides K, Image and Video Compression Standards: Algorithms and Architectures, Kluwer, Academic Publishers, 2nd edition, ISBN 0-7923-9952-8, 2003.

[17] Tanenbaum AS, Wetherall DJ, Networks Computers, Prentice Hall, United States of America, ISBN-10: 0132126958, 2011.

[18]Bovik AC. The Essential Guide to Video Processing, 2nd ed., Academic Press, United Kingdom, 2009.
[19]Roger Pressman. Software Engineering: A Practitioner's Approach, 7 edition, McGraw-Hill, United States of America, ISBN 0073375977, 2009.

[20] OMG, OMG Unified Modeling Language. Object Management Group Document Specification ptc/2012-10-24, 2012.

[21]Deitel HM and Deitel PJ, Java how to Program, 4th edition, Prentice Hall, United States of America, 2001.

[22] Marrs T and Davis S. Jboss at Work: A Practical Guide. O'Reilly Media, United States of America ISBN: 0596007345, 2005.

[23] Farley Jim, Practical JBoss Seam Projects, Apress, United States of America, ISBN-10: 1590598636, 2007.

[24] Sheldon R and Moes G, Beginning MySQL, Wiley Publishing, United States of America, 2005.

[25] Noble J, Anderson T, Braithwaite G, Casario M, Tretola R, Flex 4 Cookbook: Real-world recipes for developing Rich Internet Applications, O'Reilly Media, United States of America, ISBN: 9781449390594, 2010.

[26] Reinhardt R, Video with Adobe Flash CS4 Professional Studio Techniques, 2nd edition, Pearson Education, ISBN: 0132089386, United States of America, 2009.

[27] Sheskin David J, Handbook of parametric and nonparametric statistical procedure, 5th edition, ISBN: 978-1-4398-5801-1, Publisher CRC Press, England, 2011.

[28] Wang Y, Claypool M, RealTracer-Tools for Measuring the Performance of RealVideo on the Internet, Multimedia Tools and Applications, Publisher Springer Science, 27, p411-430, 2005.

[29] Read P, Meyer MP, Restoration of Motion Picture Film, Publisher Elsevier Butterworth - Heinemann. United Kingdom, 2000.

[30] Quilici FA, Grecco C. Colonoscopia. Lemos Editorial, ISBN: 85-7450-048-8, São Paulo, 2000.

[31] Caritá EC. Sistema de gerenciamento de imagens para ambiente hospitalar com suporte à recuperação de imagens baseada em conteúdo [Doctor Tesis]. Ribeirão Preto: Universidade de São Paulo - USP, 2006.

[32] Yu L, Jihong W. PACS and digital medicine: essential principles and modern practice. Boca Raton: Taylor and Fracis Group, ISBN: 13:978-1-4200-8366-8, 2011.

[33] Filho EVS, Passos MG, Santos BA, Oliveira SS, Melo EAG, Motta GHMB, Tavares TA, Filho GLS, Uma Ferramenta para Gerenciamento e Transmissão de Fluxos de Vídeo em Alta Definição para Telemedicina, Proceedings of XXX Simpósio Brasileiro de Redes de Computadores e Sistemas Distribuídos SBRC, 2012.

[34] Maciel JN, Machado RB, Wu FC, Lee HD, Fagundes JJ and Góes JRN. Protótipo de Conferência Multimídia e Transmissão de Dados de Experimentos 
Médicos em Tempo Real pela Web. Proceedings of VI Workshop de Informática Médica - WIM, 2006.

[35] Hung K, Zhang YT, Implementation of a WAPBased Telemedicine. IEEE Transactions On Information Technology In Biomedicine, vol. 7, no. 2, 2003.

[36] Figueredo MVM, Dias JS, Mobile Telemedicine System for Home Care and Patient Monitoring. Proceedings of the 26th Annual International Conference of the IEEE. San Francisco, CA, USA, 2004.

[37] Yousef J, Lars AN, Validation Of A Real-Time Wireless Telemedicine System, Using Bluetooth Protocol and a Mobile Phone, For Remote Monitoring Patient. In Medical Practice, European Journal Of Medical Research, Publisher I. Holzapfel, 10: p254262, 2005.

[38]Fujinon Corporation, Operation Manual. EVE Processor: VP-4400. Fujinon Corporation. v. 1.1. Japan, 2009.

[39] Chen JYC, Thropp JE. Review of Low Frame Rate Effects on Human Performance. IEEE Trans. Sys. Man Cyber., 2007. 